\title{
Postnatal verification of prenatal diagnoses established on foetal magnetic resonance imaging
}

\author{
Agnieszka Duczkowska ${ }^{1}$, Anna Olwert ${ }^{2}$, Marek Duczkowski ${ }^{1}$, Monika Bekiesińska-Figatowska ${ }^{1}$ \\ ${ }^{1}$ Institute of Mother and Child, Warsaw, Poland \\ ${ }^{2}$ Systems Research Institute, Polish Academy of Sciences, Warsaw, Poland
}

\begin{abstract}
Objectives: The role of magnetic resonance imaging, similarly to ultrasound, in the evaluation of foetal anomalies is indisputable. This gives rise to a question, whether prenatal diagnostics can replace postnatal one. To assess the diagnostic accuracy of foetal MRI in children with congenital anomalies by using postnatal MRI, X-ray/US and surgery (histopathology/autopsy) results as a reference standard.

Material and methods: 110 children were included in the analysis. All of them underwent foetal MRI, and the diagnoses were verified after birth. All the results were analysed both by: 1. evaluation of correctness of the prenatal diagnosis with the reference standard diagnosis of each patient, and 2. statistical evaluation of prenatal diagnosis using standard measures of binary diagnostic tests' abilities.

Results: The accordance of prenatal and final diagnoses was 70\%. Only $3.64 \%$ of patients were misdiagnosed. Most of the prenatal diagnoses that were incomplete (23.64\%), concerned children who underwent surgery, and among them patients with abdominal cystic laesions of undetermined origin on foetal MRI constituted the majority. In $2.73 \%$ of cases prenatal diagnoses remained inconclusive.

Conclusions: High correlation of prenatal and postnatal tests'results in the study material confirms the high value of foetal MRI in perinatal diagnostics. Comprehensive assessment of the foetus in prenatal MRI is very effective and facilitates important therapeutic decisions in the prenatal period (in utero treatment) and in perinatal care (application or withdrawal from the EXIT procedure, surgery or backtracking from neonatal resuscitation if it should bear the hallmarks of persistent therapy).

Key words: foetal magnetic resonance imaging (MRI), congenital anomalies, prenatal diagnosis, postnatal diagnosis
\end{abstract}

Ginekologia Polska 2018; 89, 5: 262-270

\section{INTRODUCTION}

The usefulness of prenatal magnetic resonance imaging (MRI) has been proved, despite very accurate visualisation of the foetus provided by modern ultrasound (US) technologies. There are indisputable indications for prenatal MRI, among them: suspicion of central nervous system (CNS) pathologies, differentiation of pulmonary pathologies and those resulting from the dislocation of abdominal organs to the chest, searching for a missing kidney and many more. This gives rise to a question, whether prenatal MRI can replace postnatal diagnostics [1, 2].

MRI should always be preceded by US and should be performed in the second trimester of pregnancy, possibly with recommendation of a control study in the third trimester
$[3,4]$, because detailed assessment of anomaly after birth usually requires general anaesthesia and anaesthetic care [5]. Establishing the correct diagnosis is important for planning place, time and mode of delivery, for treatment in utero or after birth, and also for the psychological care for the parents [6].

\section{Objectives}

The aim of the study was to assess the accuracy of prenatal diagnoses in relation to the pathologies. The reference point was the final diagnosis established after birth on:

a) MRI,

b) imaging studies other than MRI (X-ray, US),

c) surgery or autopsy and subsequent histopathological examination. 


\section{MATERIAL AND METHODS}

110 children were included into the retrospective analysis. All children had prenatal MRI performed at gestational age (GA) of 18-39 weeks. Only patients who had the final diagnosis established postnatally were included:

A - 37 children had MRI,

B - 44 children - radiography or US,

C - 29 patients had surgery (4 additionally autopsy) and a subsequent histopathological examination.

Foetal MR examinations were performed on a 1.5 Tesla scanner, in a dedicated twelve-channel HD Body Full abdominal coil, without sedation and without administration of contrast agents, and were preceded by US examinations. Each study was retrospectively analysed independently by two radiologists and only foetuses with convergent diagnoses were included into the study.

The diagnosis made on prenatal MRI was considered as correct (if confirmed by the final postnatal diagnosis), incorrect (if the diagnosis was missed), incomplete (when not all anomalies were diagnosed) or inconclusive (if an important prenatal finding was neither confirmed nor ruled out until the end of our observation).

A statistical evaluation of prenatal diagnoses was carried out using standard measures of binary diagnostic tests' abilities, i.e. sensitivity, specificity and accuracy, as well as a positive predictive value (PPV) and a negative predictive value (NPV) for:

- all single CNS anomalies,

- groups of anomalies in particular locations, i.e. the brain, the spinal canal and both together (CNS), the head and neck, the chest, the abdomen and pelvis, which includes the urinary tract anomalies as the most numerous group,

- other single defects in the chest and in the abdomen.

95\% confidence intervals $(95 \% \mathrm{Cl})$ were determined for sensitivity, specificity, PPV, NPV and accuracy with the Clopper-Pearson method. The calculations were made using the statistical $R$ package in version 3.3.1. under the GNU General Public License. To estimate the sensitivity, specificity, PPV, NPV and the accuracy of prenatal diagnoses, the epiR software [7] with the Clopper-Pearson method implemented was used.

\section{RESULTS}

A full correlation of prenatal and final diagnoses was found in $70 \%$ of cases. Prenatal diagnoses were incorrect only in $3.6 \%$ of patients and were as follows: suspected but not confirmed postnatally delayed gyrification in a 26-week foetus, unrecognised polymicrogyria in a 22-week foetus, suspected tumour of the nose base in a 24-week foetus with postnatally recognised cephalocele, and unrecognised interrupted aortic arch (IAA) in a 27-week foetus.

In as much as $23.6 \%$ of cases, prenatal diagnoses were considered incomplete, mostly in children who underwent surgery $(16 / 29$ patients $=55.2 \%)$ and abdominal cystic laesions of unknown origin constituted the majority of them.

In $2.7 \%$ of cases (3 patients), diagnoses were inconclusive. One foetus with unilateral pulmonary aplasia and vertebrae malformations had additionally diastematomyelia suspected at GA of 29 weeks, but neither postnatal imaging nor autopsy of the spinal canal was performed (the child died 3 weeks after birth). Two fetuses, both with myelomeningocoele (MMC), had an additional anomaly suspected: the first -subependymal cortical heterotopia at GA of 32 weeks, the second - diastematomyelia at GA of 28 weeks, but had no dedicated imaging performed after birth. Table 1 presents the numerical and/or percentage share of diagnoses in the analysed material.

Tables 2-5 include sensitivity, specificity, PPV, NPV and accuracy of diagnoses in relation to single anomalies or groups of pathologies in particular locations.

The analysis of 110 patients proved that prenatal MRI is both sensitive and specific, and has high PPV, NPV and accuracy for such anomalies as: ventriculomegaly, brain malformations, brain pathologies in general, CNS (brain and spinal canal) pathologies, urinary tract anomalies, abdominal and pelvic abnormalities in general (Tab. 2). For the above, $95 \% \mathrm{Cl}$ are narrow and range from about $80 \%$ to almost 100\% (Fig. 1).

For other analysed abnormalities only high specificity and NPV of prenatal MRI were found, but sensitivity and PPV of prenatal diagnoses could not have been precisely estimated - wide 95\% Cl (Tab. 3-5).

Organ and systemic distribution of the identified laesions is shown in Fig. 2.

There were 61 CNS abnormalities - 55 patients had brain anomalies (malformations and/or tumours) (Fig. 3), 15 - spinal canal and spinal cord pathologies.

Table 1. Numerical and/or percentage share of diagnoses in the analysed material

\begin{tabular}{|c|c|c|c|c|c|c|c|c|c|}
\hline \multirow[b]{2}{*}{ MRI } & \multirow[b]{2}{*}{37} & \multicolumn{2}{|c|}{ Correct } & \multicolumn{2}{|c|}{ Incorrect } & \multicolumn{2}{|c|}{ Incomplete } & \multicolumn{2}{|c|}{ Inconclusive } \\
\hline & & 26 & $70.27 \%$ & 2 & $5.41 \%$ & 8 & $21.62 \%$ & 1 & $2.70 \%$ \\
\hline US/X-ray & 44 & 39 & $88.64 \%$ & 1 & $2.27 \%$ & 2 & $4.55 \%$ & 2 & $4.55 \%$ \\
\hline Surgery & 29 & 12 & $41.38 \%$ & 1 & $3.45 \%$ & 16 & $55.17 \%$ & 0 & 0 \\
\hline Total & 110 & 77 & $70.00 \%$ & 4 & $3.64 \%$ & 26 & $23.64 \%$ & 3 & $2.73 \%$ \\
\hline
\end{tabular}


Table 2. Distribution of results of binary statistical tests. Part 1

\begin{tabular}{|c|c|c|c|c|c|c|c|c|c|c|}
\hline & TP & FP & FN & TN & & Sensitivity & Specificity & $\begin{array}{c}\text { Positive } \\
\text { predictive } \\
\text { value (PPV) }\end{array}$ & $\begin{array}{c}\text { Negative } \\
\text { predictive } \\
\text { value (NPV) }\end{array}$ & $\begin{array}{l}\text { Accuracy } \\
\text { (ACC) }\end{array}$ \\
\hline \multirow{2}{*}{ Ventriculomegaly } & \multirow{2}{*}{22} & \multirow{2}{*}{0} & \multirow{2}{*}{0} & \multirow{2}{*}{88} & $\%$ & 100.0 & 100.0 & 100.0 & 100.0 & 100.0 \\
\hline & & & & & $95 \% \mathrm{Cl}$ & $(78.1 ; 100)$ & $(93.9 ; 100)$ & $(78.1 ; 100)$ & $(93.9 ; 100)$ & $(95.1 ; 100)$ \\
\hline \multirow{2}{*}{ Brain malformations } & \multirow{2}{*}{46} & \multirow{2}{*}{0} & \multirow{2}{*}{4} & \multirow{2}{*}{60} & $\%$ & 92.0 & 100.0 & 100.0 & 93.7 & 96.4 \\
\hline & & & & & $95 \% \mathrm{Cl}$ & $(80.7 ; 97.8)$ & $(91.2 ; 100)$ & $(88.7 ; 100)$ & $(84.8 ; 98.3)$ & $(90.9 ; 99.0)$ \\
\hline \multirow{2}{*}{$\begin{array}{l}\text { Brain pathologies (including } \\
\text { malformations and tumours) }\end{array}$} & \multirow{2}{*}{51} & \multirow{2}{*}{0} & \multirow{2}{*}{4} & \multirow{2}{*}{55} & $\%$ & 92.7 & 100.0 & 100.0 & 93.2 & 96.4 \\
\hline & & & & & $95 \% \mathrm{Cl}$ & $(82.4 ; 98.0)$ & $(90.4 ; 100)$ & $(89.7 ; 100)$ & $(83.5 ; 98.1)$ & $(90.9 ; 99.0)$ \\
\hline \multirow{2}{*}{$\begin{array}{l}\text { CNS pathologies (brain and } \\
\text { spinal canal) }\end{array}$} & \multirow{2}{*}{57} & \multirow{2}{*}{0} & \multirow{2}{*}{4} & \multirow{2}{*}{49} & $\%$ & 93.4 & 100.0 & 100.0 & 92.5 & 96.4 \\
\hline & & & & & $95 \% \mathrm{Cl}$ & $(84.1 ; 98.2)$ & $(89.4 ; 100)$ & $(90.8 ; 100)$ & $(81.8 ; 97.9)$ & $(91.0 ; 99.0)$ \\
\hline \multirow{2}{*}{ Urinary tract abnormalities } & \multirow{2}{*}{24} & \multirow{2}{*}{1} & \multirow{2}{*}{0} & \multirow{2}{*}{85} & $\%$ & 100.0 & 98.8 & 96.0 & 100.0 & 99.1 \\
\hline & & & & & $95 \% \mathrm{Cl}$ & $(85.8 ; 100)$ & $(93.7 ; 100)$ & $(79.6 ; 99.9)$ & $(95.8 ; 100)$ & $(95.0 ; 100)$ \\
\hline \multirow{2}{*}{$\begin{array}{l}\text { Abdominal and pelvic } \\
\text { abnormalities }\end{array}$} & \multirow{2}{*}{44} & \multirow{2}{*}{0} & \multirow{2}{*}{0} & \multirow{2}{*}{66} & $\%$ & 100.0 & 100.0 & 100.0 & 100.0 & 100.0 \\
\hline & & & & & $95 \% \mathrm{Cl}$ & $(88.2 ; 100)$ & $(92.0 ; 100)$ & $(88.2 ; 100)$ & $(92.0 ; 100)$ & $(95.1 ; 100)$ \\
\hline
\end{tabular}

\begin{tabular}{|c|c|c|c|c|c|c|c|c|c|c|}
\hline & TP & FP & FN & TN & & Sensitivity & Specificity & $\begin{array}{l}\text { Positive } \\
\text { predictive } \\
\text { value (PPV) }\end{array}$ & $\begin{array}{c}\text { Negative } \\
\text { predictive } \\
\text { value (NPV) }\end{array}$ & $\begin{array}{c}\text { Accuracy } \\
\text { (ACC) }\end{array}$ \\
\hline \multirow{2}{*}{$\begin{array}{l}\text { Agenesis of septum } \\
\text { pellucidum }\end{array}$} & \multirow{2}{*}{14} & \multirow{2}{*}{0} & \multirow{2}{*}{0} & \multirow{2}{*}{96} & $\%$ & 100.0 & 100.0 & 100.0 & 100.0 & 100.0 \\
\hline & & & & & $95 \% \mathrm{Cl}$ & $(68.1 ; 100)$ & $(94.4 ; 100)$ & $(68.1 ; 100)$ & $(94.4 ; 100)$ & $(95.1 ; 100)$ \\
\hline \multirow{2}{*}{$\begin{array}{l}\text { Dysgenesis of corpus } \\
\text { callosum }\end{array}$} & \multirow{2}{*}{3} & \multirow{2}{*}{0} & \multirow{2}{*}{3} & \multirow{2}{*}{104} & $\%$ & 50.0 & 100.0 & 100.0 & 97.2 & 97.3 \\
\hline & & & & & $95 \% \mathrm{Cl}$ & $(11.8 ; 88.2)$ & $(94.8 ; 100)$ & $(19.4 ; 100)$ & $(92.0 ; 99.4)$ & $(92.2 ; 99.4)$ \\
\hline \multirow{2}{*}{ Agenesis of corpus callosum } & \multirow{2}{*}{8} & \multirow{2}{*}{0} & \multirow{2}{*}{0} & \multirow{2}{*}{102} & $\%$ & 100.0 & 100.0 & 100.0 & 100.0 & 100.0 \\
\hline & & & & & $95 \% \mathrm{Cl}$ & $(51.7 ; 100)$ & $(94.7 ; 100)$ & $(51.7 ; 100)$ & $(94.7 ; 100)$ & $(95.0 ; 100)$ \\
\hline \multirow{2}{*}{$\begin{array}{l}\text { Developmental } \\
\text { malformations of the cortex }\end{array}$} & \multirow{2}{*}{11} & \multirow{2}{*}{2} & \multirow{2}{*}{3} & \multirow{2}{*}{94} & $\%$ & 78.6 & 97.9 & 84.6 & 96.9 & 95.5 \\
\hline & & & & & $95 \% \mathrm{Cl}$ & $(49.2 ; 95.3)$ & $(92.7 ; 99.7)$ & $(54.6 ; 98.1)$ & $(91.2 ; 99.4)$ & $(89.7 ; 98.5)$ \\
\hline \multirow{2}{*}{ Encephalocoele } & \multirow{2}{*}{5} & \multirow{2}{*}{0} & \multirow{2}{*}{2} & \multirow{2}{*}{103} & $\%$ & 71.4 & 100.0 & 100.0 & 98.0 & 98.2 \\
\hline & & & & & $95 \% \mathrm{Cl}$ & $(29.0 ; 96.3)$ & $(94.8 ; 100)$ & $(35.9 ; 100)$ & $(93.3 ; 99.8)$ & $(93.6 ; 99.8)$ \\
\hline \multirow{2}{*}{ Chiari II malformation } & \multirow{2}{*}{7} & \multirow{2}{*}{0} & \multirow{2}{*}{1} & \multirow{2}{*}{102} & $\%$ & 87.5 & 100.0 & 100.0 & 99.0 & 99.1 \\
\hline & & & & & $95 \% \mathrm{Cl}$ & $(47.3 ; 99.7)$ & $(94.7 ; 100)$ & $(47.3 ; 100)$ & $(94.7 ; 100)$ & $(95.0 ; 100)$ \\
\hline \multirow{2}{*}{ Cerebellum anomalies } & \multirow{2}{*}{7} & \multirow{2}{*}{0} & 0 & 102 & $\%$ & 100.0 & 100.0 & 100.0 & 100.0 & 100.0 \\
\hline & & & 0 & Sט) & $95 \% \mathrm{Cl}$ & $(47.3 ; 100)$ & $(94.8 ; 100)$ & $(47.3 ; 100)$ & $(94.8 ; 100)$ & $(95.1 ; 100)$ \\
\hline Other supra- and & 8 & 0 & 1 & 101 & $\%$ & 88.9 & 100.0 & 100.0 & 99.0 & 99.1 \\
\hline infratentorial anomalies & - & & & & $95 \% \mathrm{Cl}$ & $(51.8 ; 99.7)$ & $(94.7 ; 100)$ & $(51.8 ; 100)$ & $(94.7 ; 100)$ & $(95.0 ; 100)$ \\
\hline Narm & 1 & 0 & 1 & 100 & $\%$ & 50.0 & 100.0 & 100.0 & 99.0 & 99.1 \\
\hline 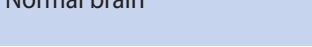 & 1 & 0 & 1 & 100 & $95 \% \mathrm{Cl}$ & $(1.26 ; 98.7)$ & $(95.0 ; 100)$ & $(1.26 ; 100)$ & $(95.0 ; 100)$ & $(95.0 ; 100)$ \\
\hline $\mathrm{B}_{n \rightarrow 0}$ & 5 & 0 & 0 & $11+2-1$ & $\%$ & 100.0 & 100.0 & 100.0 & 100.0 & 100.0 \\
\hline 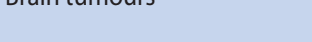 & 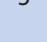 & r & 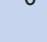 & S & $95 \% \mathrm{Cl}$ & $(35.9 ; 100)$ & $(94.9 ; 100)$ & $(35.9 ; 100)$ & $(94.9 ; 100)$ & $(95.0 ; 100)$ \\
\hline
\end{tabular}

Abdominal and pelvic anomalies constituted the second largest group in the analysed material -44 cases (Tab. 2). Chest laesions were found in 9 patients (Tab. 4).

Finally, 3 patients included in the analysis had cystic neck laesions - lymphangiomas.

\section{DISCUSSION}

Although there are many publications confirming the usefulness of prenatal MRI in the evaluation of foetal anomalies, only few of them compare pre- and postnatal diagnoses, but dealing with particular organs, systems or parts of the 
Table 4. Distribution of results of binary statistical tests. Part 3

\begin{tabular}{|c|c|c|c|c|c|c|c|c|c|c|}
\hline & TP & FP & FN & TN & & Sensitivity & Specificity & $\begin{array}{l}\text { Positive } \\
\text { predictive } \\
\text { value (PPV) }\end{array}$ & $\begin{array}{c}\text { Negative } \\
\text { predictive } \\
\text { value (NPV) }\end{array}$ & $\begin{array}{l}\text { Accuracy } \\
\text { (ACC) }\end{array}$ \\
\hline \multirow{2}{*}{$\begin{array}{l}\text { Head tumours excluding the } \\
\text { brain }\end{array}$} & \multirow{2}{*}{3} & \multirow{2}{*}{2} & \multirow{2}{*}{0} & \multirow{2}{*}{105} & \multirow{2}{*}{$\begin{array}{c}\% \\
95 \% \mathrm{Cl}\end{array}$} & 100.0 & 98.1 & 60.0 & 100.0 & 98.2 \\
\hline & & & & & & $(19.4 ; 100)$ & $(93.4 ; 99.8)$ & $(14.7 ; 94.7)$ & $(94.9 ; 100)$ & $(93.6 ; 99.8)$ \\
\hline \multirow{2}{*}{$\begin{array}{l}\text { Head tumours including the } \\
\text { brain }\end{array}$} & \multirow{2}{*}{8} & \multirow{2}{*}{2} & \multirow{2}{*}{0} & \multirow{2}{*}{100} & \multirow{2}{*}{$\begin{array}{c}\% \\
95 \% \mathrm{Cl}\end{array}$} & 100.0 & 98.0 & 80.0 & 100.0 & 98.2 \\
\hline & & & & & & $(51.7 ; 100)$ & $(93.1 ; 99.8)$ & $(44.4 ; 97.5)$ & $(94.6 ; 100)$ & $(93.6 ; 99.8)$ \\
\hline \multirow{2}{*}{$\begin{array}{l}\text { Head pathologies excluding } \\
\text { the brain }\end{array}$} & \multirow{2}{*}{6} & \multirow{2}{*}{2} & \multirow{2}{*}{0} & \multirow{2}{*}{102} & \multirow{2}{*}{$\begin{array}{c}\% \\
95 \% \mathrm{Cl}\end{array}$} & 100.0 & 98.1 & 75.0 & 100.0 & 98.2 \\
\hline & & & & & & $(42.1 ; 100)$ & $(93.2 ; 99.8)$ & $(34.9 ; 96.8)$ & $(94.7 ; 100)$ & $(93.6 ; 99.8)$ \\
\hline \multirow{2}{*}{ Spinal dysraphism } & \multirow{2}{*}{8} & \multirow{2}{*}{0} & \multirow{2}{*}{1} & \multirow{2}{*}{101} & $\%$ & 88.9 & 100.0 & 100.0 & 99.0 & 99.1 \\
\hline & & & & & $95 \% \mathrm{Cl}$ & $(51.8 ; 99.7)$ & $(94.7 ; 100)$ & $(51.8 ; 100)$ & $(94.7 ; 100)$ & $(95.0 ; 100)$ \\
\hline \multirow{2}{*}{ Other spinal cord anomalies } & \multirow{2}{*}{4} & \multirow{2}{*}{2} & \multirow{2}{*}{0} & \multirow{2}{*}{104} & $\%$ & 100.0 & 98.1 & 66.7 & 100.0 & 98.2 \\
\hline & & & & & $95 \% \mathrm{Cl}$ & $(28.4 ; 100)$ & $(93.4 ; 99.8)$ & $(22.3 ; 95.7)$ & $(94.8 ; 100)$ & $(93.6 ; 99.8)$ \\
\hline \multirow{2}{*}{ Vertebrae malformations } & \multirow{2}{*}{1} & \multirow{2}{*}{0} & \multirow{2}{*}{3} & \multirow{2}{*}{106} & $\%$ & 25.0 & 100 & 100.0 & 97.2 & 97.3 \\
\hline & & & & & $95 \% \mathrm{Cl}$ & $(0.6 ; 80.6)$ & $(94.9 ; 100)$ & $(1.3 ; 100)$ & $(92.2 ; 99.4)$ & $(92.2 ; 99.4)$ \\
\hline \multirow{2}{*}{ Anterior meningocoele } & 1 & 0 & 0 & 100 & $\%$ & 100.0 & 100.0 & 100.0 & 100.0 & 100.0 \\
\hline & 1 & 0 & 0 & 100 & $95 \% \mathrm{Cl}$ & $(1.26 ; 100)$ & $(95.0 ; 100)$ & $(1.26 ; 100)$ & $(95.0 ; 100)$ & $(95.0 ; 100)$ \\
\hline Sacrococryoul toratoma & 2 & 0 & 2 & 106 & $\%$ & 50.0 & 100.0 & 100.0 & 98.1 & 98.2 \\
\hline Jactucuchyear teratuma & 2 & O & 2 & 100 & $95 \% \mathrm{Cl}$ & $(6.8 ; 93.2)$ & $(94.9 ; 100)$ & $(9.4 ; 100)$ & $(93.5 ; 99.8)$ & $(93.6 ; 99.8)$ \\
\hline Sninal canalanomalies & 14 & 0 & 1 & 95 & $\%$ & 93.3 & 100.0 & 100.0 & 99.0 & 99.1 \\
\hline 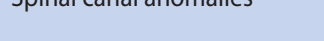 & 14 & O & 1 & كנ & $95 \% \mathrm{Cl}$ & $(68.1 ; 99.8)$ & $(94.3 ; 100)$ & $(68.1 ; 100)$ & $(94.3 ; 100)$ & $(95.0 ; 100)$ \\
\hline
\end{tabular}

Table 5. Distribution of results of binary statistical tests. Part 4

\begin{tabular}{|c|c|c|c|c|c|c|c|c|c|c|}
\hline & TP & FP & FN & TN & & Sensitivity & Specificity & $\begin{array}{c}\text { Positive } \\
\text { predictive } \\
\text { value (PPV) }\end{array}$ & $\begin{array}{c}\text { Negative } \\
\text { predictive } \\
\text { value (NPV) }\end{array}$ & $\begin{array}{c}\text { Accuracy } \\
\text { (ACC) }\end{array}$ \\
\hline \multirow{2}{*}{ Pulmonary sequestration } & \multirow{2}{*}{2} & \multirow{2}{*}{0} & \multirow{2}{*}{0} & \multirow{2}{*}{108} & $\%$ & 100.0 & 100.0 & 100.0 & 100.0 & 100.0 \\
\hline & & & & & $95 \% \mathrm{Cl}$ & $(9.4 ; 100)$ & $(95.0 ; 100)$ & $(9.4 ; 100)$ & $(95.0 ; 100)$ & $(95.0 ; 100)$ \\
\hline \multirow{2}{*}{ CPAM } & \multirow{2}{*}{1} & \multirow{2}{*}{0} & \multirow{2}{*}{0} & \multirow{2}{*}{109} & $\%$ & 100.0 & 100.0 & 100.0 & 100.0 & 100.0 \\
\hline & & & & & $95 \% \mathrm{Cl}$ & $(1.26 ; 100)$ & $(95.0 ; 100)$ & $(1.26 ; 100)$ & $(95.0 ; 100)$ & $(95.0 ; 100)$ \\
\hline \multirow{2}{*}{ Pulmonary aplasia } & \multirow{2}{*}{1} & \multirow{2}{*}{0} & \multirow{2}{*}{0} & \multirow{2}{*}{109} & $\%$ & 100.0 & 100.0 & 100.0 & 100.0 & 100.0 \\
\hline & & & & & $95 \% \mathrm{Cl}$ & $(1.26 ; 100)$ & $(95.0 ; 100)$ & $(1.26 ; 100)$ & $(95.0 ; 100)$ & $(95.0 ; 100)$ \\
\hline \multirow{2}{*}{ IAA } & \multirow{2}{*}{0} & \multirow{2}{*}{0} & \multirow{2}{*}{1} & \multirow{2}{*}{109} & $\%$ & 0.0 & 100.0 & $\mathrm{NaN}$ & 99.0 & 99.1 \\
\hline & & & & & $95 \% \mathrm{Cl}$ & $(0 ; 98.7)$ & $(95.0 ; 100)$ & $(0 ; 100)$ & $(95.0 ; 100)$ & $(95.0 ; 100)$ \\
\hline \multirow{2}{*}{ Other chest anomalies } & \multirow{2}{*}{3} & \multirow{2}{*}{0} & \multirow{2}{*}{0} & \multirow{2}{*}{107} & $\%$ & 100.0 & 100.0 & 100.0 & 100.0 & 100.0 \\
\hline & & & & & $95 \% \mathrm{Cl}$ & $(19.4 ; 100)$ & $(94.9 ; 100)$ & $(19.4 ; 100)$ & $(94.9 ; 100)$ & $(95.0 ; 100)$ \\
\hline \multirow{2}{*}{ Ddiaphragmatic hernia } & \multirow{2}{*}{0} & \multirow{2}{*}{0} & \multirow{2}{*}{1} & \multirow{2}{*}{109} & $\%$ & 0.0 & 100.0 & $\mathrm{NaN}$ & 99.0 & 99.1 \\
\hline & & & & & $95 \% \mathrm{Cl}$ & $(0 ; 98.7)$ & $(95.0 ; 100)$ & $(0 ; 100)$ & $(95.0 ; 100)$ & $(95.0 ; 100)$ \\
\hline \multirow{2}{*}{ Chest malformations } & \multirow{2}{*}{7} & \multirow{2}{*}{0} & 2 & 101 & $\%$ & 77.8 & 100.0 & 100.0 & 98.0 & 98.2 \\
\hline & & & 2 & 101 & $95 \% \mathrm{Cl}$ & $(40.0 ; 97.2)$ & $(94.7 ; 100)$ & $(47.3 ; 100)$ & $(93.2 ; 99.8)$ & $(93.6 ; 99.8)$ \\
\hline Jiverff th of & ? & 0 & 2 & 106 & $\%$ & 50.0 & 100.0 & 100.0 & 98.1 & 98.2 \\
\hline Liver tocal laesionis & 2 & 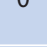 & 2 & 100 & $95 \% \mathrm{Cl}$ & $(6.8 ; 93.2)$ & $(94.9 ; 100)$ & $(9.4 ; 100)$ & $(93.5 ; 99.8)$ & $(93.6 ; 99.8)$ \\
\hline abdominal and pelvic cystic & 10 & ? & 0 & 00 & $\%$ & 100.0 & 98.0 & 83.3 & 100.0 & 98.2 \\
\hline laesions & 10 & 2 & 0 & 90 & $95 \% \mathrm{Cl}$ & $(58.7 ; 100)$ & $(93.0 ; 99.8)$ & $(51.6 ; 97.9)$ & $(94.5 ; 100)$ & $(93.6 ; 99.8)$ \\
\hline Abdominal and pelvic solid & 14 & 0 & 0 & 96 & $\%$ & 100.0 & 100.0 & 100.0 & 100.0 & 100.0 \\
\hline and cystic tumours & & & & & $95 \% \mathrm{Cl}$ & $(68.1 ; 100)$ & $(94.4 ; 100)$ & $(68.1 ; 100)$ & $(94.4 ; 100)$ & $(95.1 ; 100)$ \\
\hline
\end{tabular}


body, do not asses the whole foetus. Complex evaluation of the foetus is of great importance taking into account possible multi-system anomalies.

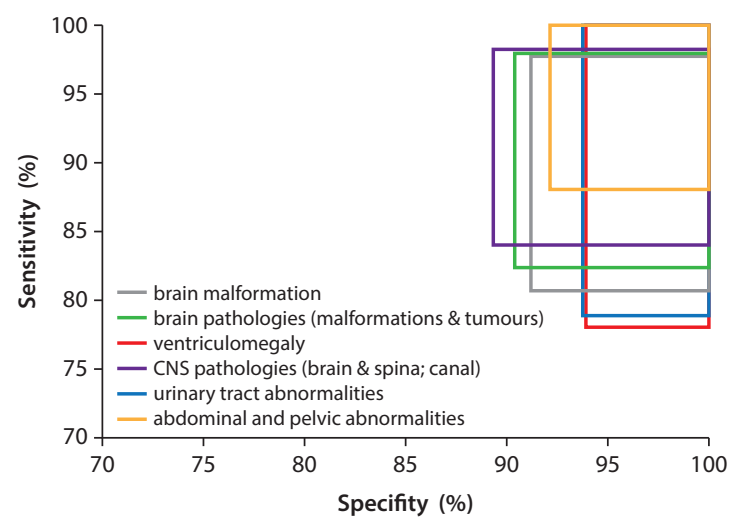

Figure 1.95\% confidence intervals for selected pathologies
The aim of this paper is to supplement the literature with an analysis of whole body foetal MRI verified by postnatal examinations.

Our analysis proves that in most cases (70\%) postnatal diagnostics does not significantly contribute to prenatal MRI. However, among the described pathologies, there are some diagnostic challenges and only these are discussed below. Important findings enabling the correct diagnosis are highlighted.

\section{Brain abnormalities}

Congenital abnormalities of the CNS are main indications for prenatal MRI. The majority of patients in our material had ventriculomegaly, which - detected on US — raised the suspicion of coexistent anomalies, among them malformations of cortical development (MCD). The foetus age plays the key role in making diagnosis of MCD on prenatal MRI due to the

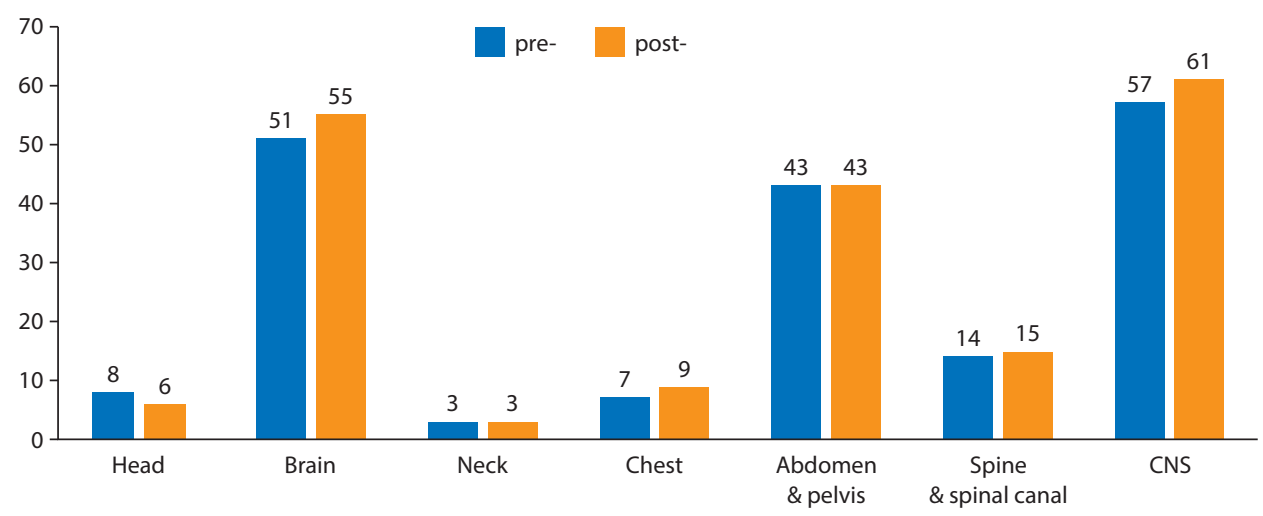

Figure 2. Organ and systemic distribution of the lesions identified in the analysed material

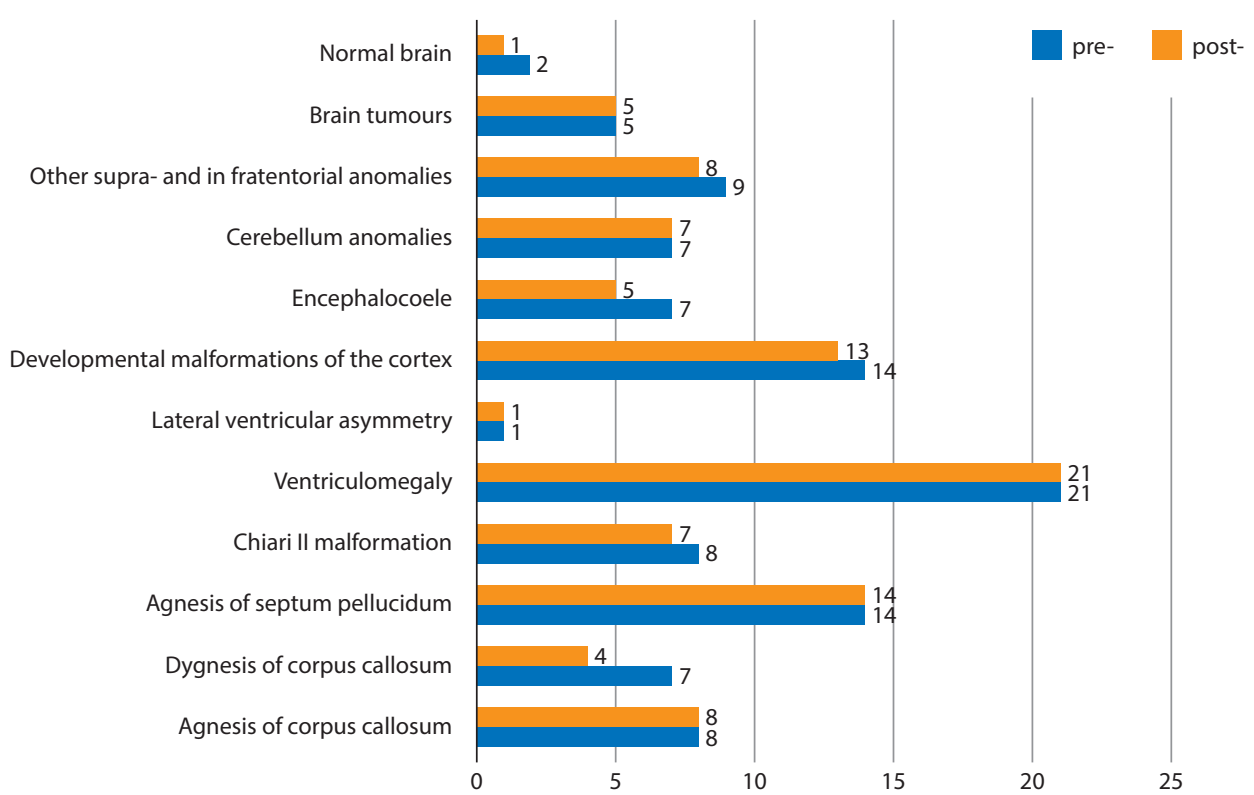

Figure 3. The distribution of brain anomalies in the analysed material 
neocortex formation. MCD, found in our patients, include: tuberous sclerosis complex, cortical heterotopy, polimicrogyria and Walker-Warburg syndrome (WWS), which is type II ("cobblestone") lissencephaly. Prenatal diagnosis of WWS is not straightforward because either confirmation or exclusion of lissencephaly on MRI is feasible after about 30 gestational weeks (GW), when most of cerebral sulci and gyri are formed [8]. Our patient with WWS was correctly diagnosed as early as 22 GW. MRI revealed vermian hypoplasia, flattened ventral aspect of the pons, which had a characteristic "z-like" configuration, thickened tectum and kinking of the brain stem - features of WWS, considered as the most important to make the diagnosis [9], but undetectable on US.

Atretic cephalocoele usually occurs in parietal or occipital region and may be associated with venous anomalies. Features suggesting the diagnosis postnatally, may still be in normal range at the time of prenatal MRI, such as vertical position of the straight sinus - abnormal after birth but physiological for the foetus (Fig. 4). This makes the correct diagnosis difficult, as it was in the case of our patient, examined at GA of 22, when aetiology of a small fluid-filled pouch on the head remained uncertain. In such cases postnatal MRI is essential.

Transsellar transsphenoidal encephalocoele is a kind of basal encephalocoele with only several dozens of cases described in the literature [10]. The only patient with this entity in our material was diagnosed on MRI at GA of 28. Abnormal fluid-filled space extending from the sella caudally and anteriorly to the nasopharynx and incomplete bony skull base, hypertelorism, cleft lip and palate were characteristic. In those children the correct diagnosis has significant implications as some postnatal procedures (e.g. intubation) can injure the encephalocoele and cause cerebrospinal fluid leak.

Holoprosencephaly (HPE) was suspected on US in one child. MRI at $18 \mathrm{GW}$ revealed incomplete separation of cerebral hemispheres anteriorly, developed frontal horns of lateral ventricles and third ventricle, separated thalami, and one very wide ventricle posteriorly, with extreme thinning of the cerebral mantle in the parietal and occipital lobes, which raised the suspicion of lobar HPE. Postnatal MRI on day 1 confirmed prenatal findings and additionally revealed foci of subependymal heterotopia, which could not have been appreciated at $18 \mathrm{GW}$ (Fig. 5). Other findings included dysgenesis of the anterior falx and of septum pellucidum. The imaging features of the posterior brain in this patient fit to the diagnosis of alobar HPE. However, correctly developed frontal horns of the lateral ventricles and separated basal ganglia are features of lobar HPE. The evaluation of this anomaly was impeded by severe ventriculomegaly. The distinction between middle interhemispheric variant (MIHV) and an undescribed till now anomaly belonging to the HPE spectrum will presumably be made on a follow-up MRI after the implantation of a ventriculoperitoneal valve. As stated by the authority in the field of brain defects, A. J. Barkovich, "the authors continue to find more, as yet unpublished, (...) malformations. It is likely that an increasing number will be discovered as the quality of brain imaging improves, with higher field strength magnetic resonance scanners and as diffusion tensor tractographic methods become more robust" [11].

\section{Abdominal and pelvic abnormalities}

Among patients with abdominal and pelvic anomalies, 2 children were incompletely diagnosed on prenatal MRI at 31-32 GW (both had rectal atresia unrecognised), and subsequently had to be reoperated. Retrospectively we assessed that there was no reason to suspect the anomaly [12]. Probably low atresia (in the distal part of rectum) was the cause of the misdiagnosis. One of these children (with omphalocoele) beside rectal atresia had also oesophageal atresia (EA) unrecognised. Polyhydramnios and empty or small stomach can help to make the diagnosis of EA, but they occur only between a third and half of cases [13]. Visualisation of dilated, blind-ending, fluid filled proximal

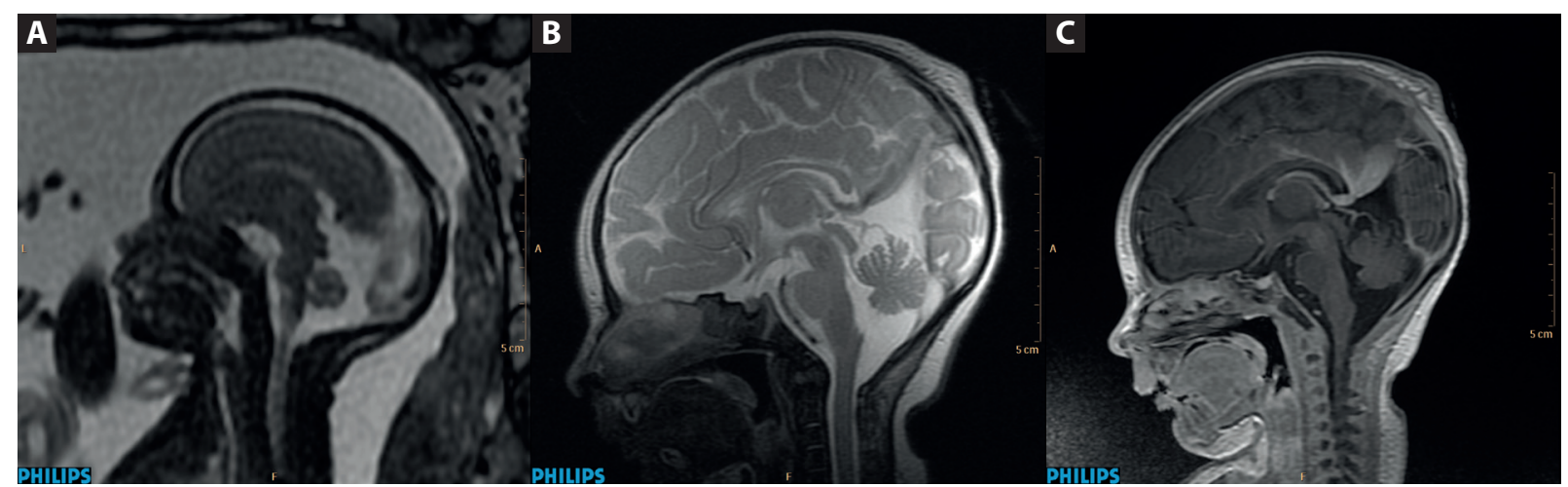

Figure 4. Atretic cephalocoele. A. SSFSE/T2, sagittal plane, foetal MRI, 22 GW. B. FSE/T2, sagittal plane, postnatal MRI. C. Vertical course of the straight sinus. SE/T1, post-Gd, sagittal plane, postnatal MRI 


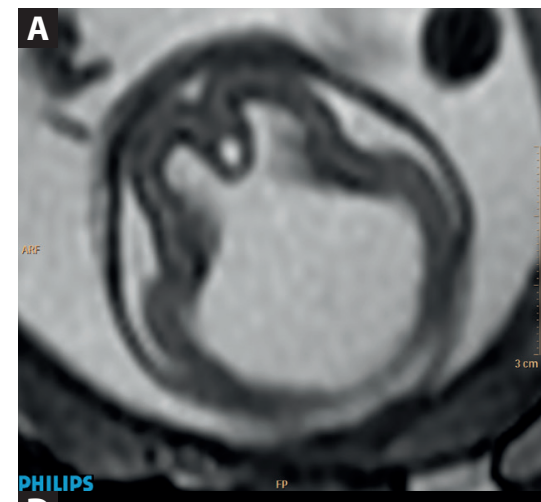

D
B

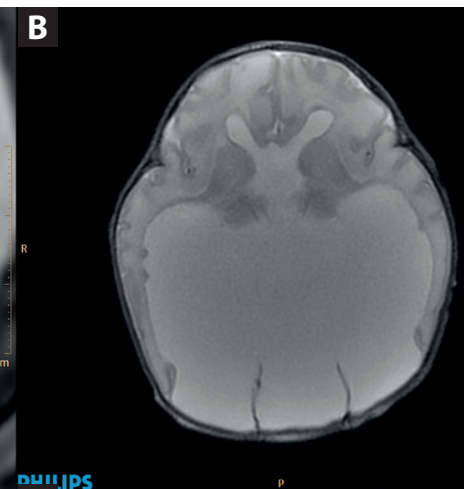

E
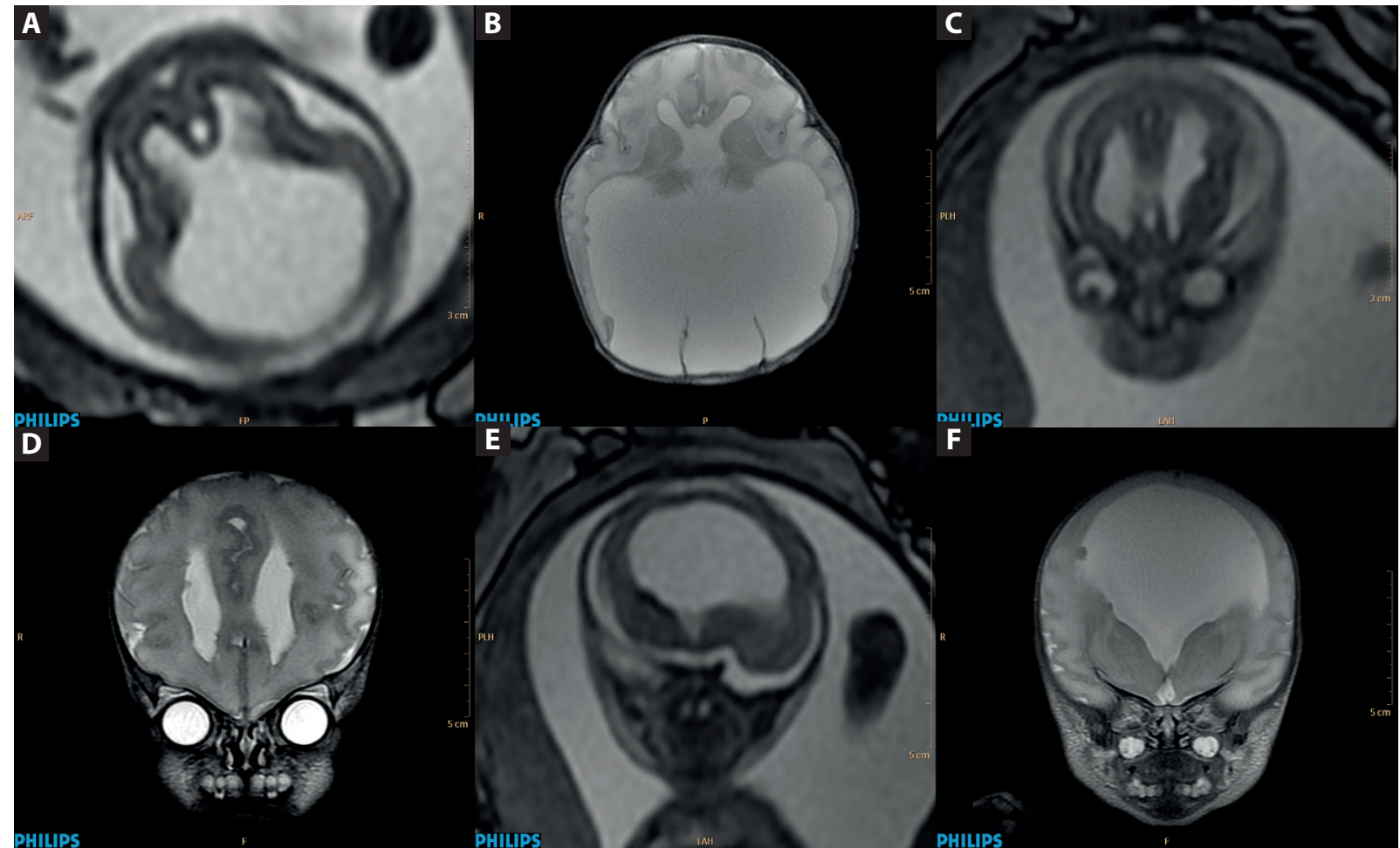

Figure 5. Holoprosencephaly - description of figures in the text. A. SSFSE/T2, axial plane, foetal MRI, 18 GW. B. FSE/T2, axial plane, postnatal MRI. C, E. SSFSE/T2, coronal plane, foetal MRI. D, F. FSE/T2, coronal plane, postnatal MRI
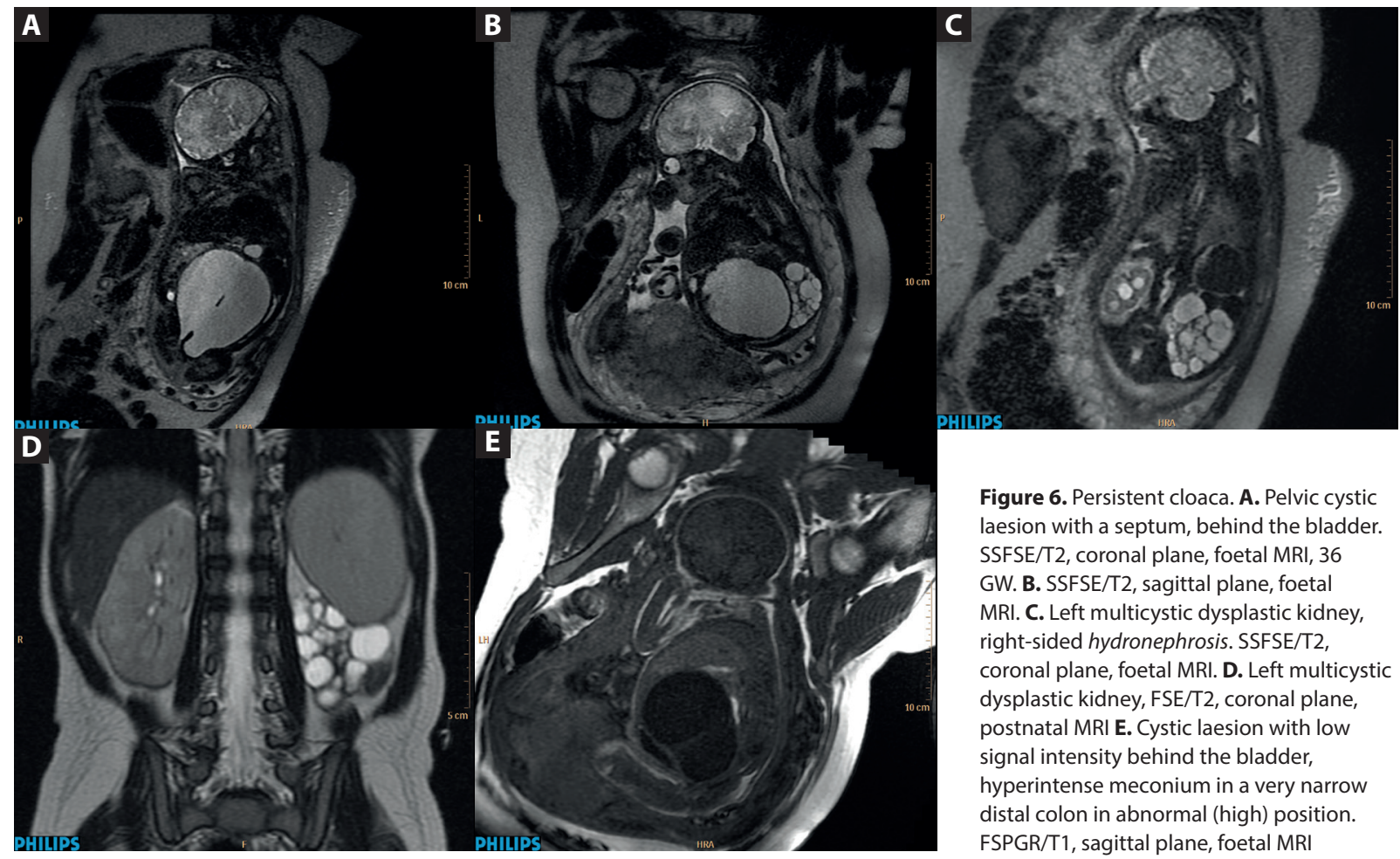

Figure 6. Persistent cloaca. A. Pelvic cystic laesion with a septum, behind the bladder. SSFSE/T2, coronal plane, foetal MRI, 36 GW. B. SSFSE/T2, sagittal plane, foetal MRI. C. Left multicystic dysplastic kidney, right-sided hydronephrosis. SSFSE/T2, coronal plane, foetal MRI. D. Left multicystic dysplastic kidney, FSE/T2, coronal plane, postnatal MRI E. Cystic laesion with low signal intensity behind the bladder, hyperintense meconium in a very narrow distal colon in abnormal (high) position. FSPGR/T1, sagittal plane, foetal MRI

oesophagus (oesophageal pouch) is crucial [14-16]. Nevertheless, prenatal diagnosis of EA remains a challenge $[13,17]$.

Persistent cloaca requires surgical treatment in the first days of life, therefore early diagnosis is of great importance [18].
The only patient with this entity in our material (a girl examined at GA of 36 weeks) had a midline septated cyst behind the bladder (Fig. 6A, B), which was suspected of hydrometrocolpos in a septated uterus. Our patient additionally 
had right-sided hydronephrosis and a left-sided multicystic dysplastic kidney (Fig. 6C, D). Abnormal position of the distal colon with meconium (at the upper half of the pelvic cyst) was missed on foetal MRI (Fig. 6E). The newborn had surgery, and the final diagnosis of cloaca was intraoperative. According to the literature, such signs as: pelvic cystic mass, dilated bowel loops, high position of the distal bowel and urinary tract anomalies should raise suspicion of persistent cloaca [18, 19].

In our material there were such abdominal cystic laesions, as: 1 duplication of the small intestine, 1 duplication of the duodenum, 1 mesenteric cyst and 1 cystic teratoma, but in none of these cases the origin of cystic laesion was determined on foetal MRI. In spite of reports in the literature emphasizing the usefulness of MRI in assessing both the origin and nature of foetal abdominal laesions, including cystic ones [20-23], our experience proves limited possibilities in differentiation of these pathologies.

Vascular anomalies (tumours and malformations) constitute a wide spectrum of pathologies which affect mainly infants and children [24]. In our material there is 1 boy suspected of hepatic haemangioma on MRI at $31 \mathrm{GW}$. On a postnatal MRI performed outside our institute, diagnosis of a vascular malformation was made. Considering the confusing nomenclature, doubts whether the final diagnosis was correct are justified [24], as hepatic vascular malformations (pathological connections between dysplastic vessels without a component of a tissue mass) are very rare, while hepatic haemangiomas are the most prevalent benign liver masses in early infancy $[25,26]$. A follow-up imaging study should be planned to assess possible dynamics of the anomaly, as haemangiomas often involute, while vascular malformations may progress but never regress.

Liver tumours account for about $5 \%$ of all congenital tumours [27]. Mesenchymal hamartoma of the liver is the second (after haemangioma) most common congenital liver tumour (constitutes about 23\%) [28]. Its origin is not always clear, as it was both in a girl examined prenatally at our centre at $30 \mathrm{GW}$ (final diagnosis was made postnatally after surgery), and in 3 patients analysed by Alamo et al. [27].

Many tumours do not have typical and specific imaging features, so the main role of imaging is to provide information about their location, extent and possible complications, so that the most appropriate treatment can be planned [27].

Blue Rubber Bleb Nevus Syndrome (BRBNS, Bean syndrome) is a rare congenital anomaly characterized by the presence of multiple venous malformations (VMs) located in the skin, gastrointestinal tract (GIT) and in other organs. They can cause GIT bleeding, which — when acute - can be fatal [29].

First of the two patients with BRBNS in our material had an abdominal cystic laesion visualised on prenatal MRI at $25 \mathrm{GW}$, second had a tongue tumour demonstrated on MRI at
GA of 33. Both laesions were found to be VMs. Both patients had skin nodules as well. In BRBNS the diameter of skin nodules can range from $1 \mathrm{~mm}$ to $10 \mathrm{~cm}$ [30], but most are approximately a few millimeters in size, so it is impossible to appreciate them on prenatal MRI. Hence, the role of foetal MRI is not to diagnose the rarely occurring BRBNS, but to recognise the vascular malformation and to facilitate the final diagnosis after delivery.

\section{Chest abnormalities}

Interrupted Aortic Arch (IAA) occurs relatively rarely, but it causes early life-threatening symptoms, and early diagnosis is therefore crucial. The only patient with IAA in our study, had foetal MRI performed at $27 \mathrm{GW}$ because of a complex heart defect detected on US. MRI did not add new findings and the final diagnosis was made just after birth on echocardiography (ECHO).

New papers dealing with cardiovascular defects on prenatal MRI have been published in the recent years [31-34]. Their authors emphasize that ECHO remains the first diagnostic test, and MRI has a complementary role. For the assessment of the heart and large vessels, it is necessary to perform Fast Imaging Employing Steady-state Acquisition (FIESTA) sequences, also in the cine option, in addition to the routinely used Single-Shot Fast Spin Echo (SSFSE) sequence. Appropriate planes, i.e. a four-chamber section and an axial cross-section through the upper mediastinum, showing the aortic arch and its relation to the superior vena cava and trachea, should be applied, analogically to the three-vessel and tracheal view in the ECHO study [33]. In case of IAA the aortic arch will not be visualised [33].

\section{CONCLUSIONS}

High correlation of prenatal and postnatal tests' results in the study material (70\% of compatible pre- and postnatal diagnoses versus $3.6 \%$ of incorrect prenatal diagnoses) confirms the high value of foetal MRI in perinatal diagnostics.

Comprehensive assessment of the foetus in prenatal MRI is very effective and facilitates important therapeutic decisions in the prenatal period (in utero treatment) and in perinatal care (application or withdrawal from the EXIT procedure, surgery or backtracking from neonatal resuscitation if it should bear the hallmarks of persistent therapy).

\section{Conflict of interest}

The authors declare no conflict of interest. The authors did not receive payment for the publication.

\section{REFERENCES}

1. Perrone A, Savelli S, Maggi C, et al. Magnetic resonance imaging versus ultrasonography in fetal pathology. Radiol Med. 2008; 113(2): 225-241, doi: 10.1007/s1 1547-008-0242-0, indexed in Pubmed: 18386124.

2. Peruzzi P, Corbitt RJ, Raffel C. Magnetic resonance imaging versus ultrasonography for the in utero evaluation of central nervous system anomalies. J Neurosurg Pediatr. 2010; 6(4): 340-345, doi: 10.3171/2010.7.PEDS09511, indexed in Pubmed: 20887106. 
3. Levine D. Timing of MRI in pregnancy, repeat exams, access, and physician qualifications. Semin Perinatol. 2013; 37(5): 340-344, doi: 10.1053/j. semperi.2013.06.011, indexed in Pubmed: 24176157.

4. Bulas D, Egloff A. Benefits and risks of MRI in pregnancy. Semin Perinatol. 2013; 37(5): 301-304, doi: 10.1053/j.semperi.2013.06.005, indexed in Pubmed: 24176150.

5. REEVES MJ, WHITBY EH, PALEY M, et al. THE CURRENT ROLE OF FETAL MAGNETIC RESONANCE IMAGING. Fetal and Maternal Medicine Review. 2008; 19(01), doi: 10.1017/s096553950800209x.

6. Bekiesinska-Figatowska M, Herman-Sucharska I, Romaniuk-Doroszewska A, et al. Diagnostic problems in case of twin pregnancies: US vs. MRI study. J Perinat Med. 2013; 41(5): 535-541, doi: 10.1515/jpm-2012-0290, indexed in Pubmed: 23612626.

7. Stevenson $M$, Nunes $T$, Heuer $C$, et al. epiR: Tools for the Analysis of Epidemiological Data, R package version 0.9-79. 2016; Available from: https://CRAN. R-project org/package=epiR. ; 2016.

8. Saleem SN. Fetal MRI: An approach to practice: A review. J Adv Res. 2014; 5(5): 507-523, doi: 10.1016/j.jare.2013.06.001, indexed in Pubmed: 25685519.

9. Whitehead MT, Fricke ST, Gropman AL. Structural brain defects. Clin Perinatol. 2015; 42(2):337-61, ix, doi: 10.1016/j.clp.2015.02.007, indexed in Pubmed: 26042908.

10. Mahapatra AK. Anterior encephalocele - AlIMS experience a series of 133 patients. J Pediatr Neurosci. 2011; 6(Suppl 1): S27-S30, doi: 10.4103/1817-1745.85706, indexed in Pubmed: 22069427.

11. Barkovich AJ, Millen KJ, Dobyns WB. A developmental and genetic classification for midbrain-hindbrain malformations. Brain. 2009; 132(Pt 12): 3199-3230, doi: 10.1093/brain/awp247, indexed in Pubmed: 19933510.

12. Podberesky DJ, Towbin AJ, Eltomey MA, et al. Magnetic resonance imaging of anorectal malformations. Magn Reson Imaging Clin N Am. 2013; 21(4): 791-812, doi: 10.1016/j.mric.2013.04.010, indexed in Pubmed: 24183526.

13. Spaggiari E, Faure G, Rousseau V, et al. Performance of prenatal diagnosis in esophageal atresia. Prenat Diagn. 2015; 35(9): 888-893, doi: 10.1002/pd.4630, indexed in Pubmed: 26058746.

14. Hochart $V$, Verpillat $P$, Langlois $C$, et al. The contribution of fetal MR imaging to the assessment of oesophageal atresia. Eur Radiol. 2015; 25(2): 306-314, doi: 10.1007/s00330-014-3444-y, indexed in Pubmed: 25304819.

15. Ethun $\mathrm{CG}$, Fallon $\mathrm{SC}$, Cassady $\mathrm{Cl}$, et al. Fetal MRI improves diagnostic accuracy in patients referred to a fetal center for suspected esophageal atresia. J Pediatr Surg. 2014; 49(5): 712-715, doi: 10.1016/j.jpedsurg.2014.02.053, indexed in Pubmed: 24851753.

16. Fallon SC, Ethun CG, Olutoye OO, et al. Comparing characteristics and outcomes in infants with prenatal and postnatal diagnosis of esophageal atresia. J Surg Res. 2014; 190(1): 242-245, doi: 10.1016/j.jss.2014.03.068, indexed in Pubmed: 24768139.

17. Garabedian C, Verpillat P, Czerkiewicz I, et al. Does a combination of ultrasound, MRI, and biochemical amniotic fluid analysis improve prenatal diagnosis of esophageal atresia? Prenat Diagn. 2014; 34(9): 839-842, doi: 10.1002/pd.4376, indexed in Pubmed: 24706336.

18. Peiro JL, Scorletti F, Sbragia L. Prenatal diagnosis of cloacal malformation. Semin Pediatr Surg. 2016; 25(2): 71-75, doi: 10.1053/j.sempedsurg.2015.11.004, indexed in Pubmed: 26969229.

19. Livingston JC, Elicevik M, Breech L, et al. Persistent cloaca: a 10-year review of prenatal diagnosis. J Ultrasound Med. 2012; 31(3): 403-407, indexed in Pubmed: 22368130.
20. Inaoka $\mathrm{T}$, Sugimori $\mathrm{H}$, Sasaki $\mathrm{Y}$, et al. VIBE MRI for evaluating the normal and abnormal gastrointestinal tract in fetuses. AJR Am J Roentgenol. 2007; 189(6): W303-W308, doi: 10.2214/AJR.07.2063, indexed in Pubmed: 18029839.

21. Veyrac C, Couture A, Saguintaah M, et al. MRI of fetal GI tract abnormalities. Abdom Imaging. 2004; 29(4): 411-420, doi: 10.1007/s00261-003-0147-2, indexed in Pubmed: 15136891.

22. Hugele $F$, Dumont $C$, Boulot $P$, et al. Does prenatal MRI enhance fetal diagnosis of intra-abdominal cysts? Prenat Diagn. 2015; 35(7): 669-674, doi: 10.1002/pd.4590, indexed in Pubmed: 25754771.

23. Gupta P, Sharma R, Kumar S, et al. Role of MRI in fetal abdominal cystic masses detected on prenatal sonography. Arch Gynecol Obstet. 2010; 281(3): 519-526, doi: 10.1007/s00404-009-1190-1, indexed in Pubmed: 19672611.

24. Wassef M, Blei F, Adams D, et al. ISSVA Board and Scientific Committee. Vascular Anomalies Classification: Recommendations From the International Society for the Study of Vascular Anomalies. Pediatrics. 2015; 136(1): e203-e214, doi: 10.1542/peds.2014-3673, indexed in Pubmed: 26055853.

25. Agha HM, Zakaria R, Mostafa FA, et al. Regression of a large congenital hepatic arteriovenous malformation. Tex Heart Inst J. 2015; 42(2): 184-187, doi: 10.14503/THIJ-13-3660, indexed in Pubmed: 25873838.

26. Alomari $\mathrm{Al}, \mathrm{Al}$ Masalmeh $\mathrm{O}$, Shaikh $\mathrm{R}$, et al. Hepatic failure in a rapidly involuting congenital hemangioma of the liver: failure of embolotherapy. Pediatr Radiol. 2009; 39(10): 1118-1123, doi: 10.1007/s00247-009-1346-y, indexed in Pubmed: 19588131.

27. Alamo L, Perrin L, Vial $Y$, et al. Prenatal imaging of congenital hepatic tumors: a report of three cases. Clin Imaging. 2017; 41: 112-117, doi: 10.1016/j.clinimag.2016.10.003, indexed in Pubmed: 27840262.

28. Franchi-Abella S, Gorincour G, Avni F, et al. SFIPP-GRRIF (Société Francophone d'Imagerie Pédiatrique et Périnatale-Groupe de Recherche Radiopédiatrique en Imagerie Foetale). Hepatic haemangioma-prenatal imaging findings, complications and perinatal outcome in a case series. Pediatr Radiol. 2012; 42(3): 298-307, doi: 10.1007/s00247-011-2214-0, indexed in Pubmed: 21928049.

29. Colletti $G$, lerardi AM. Understanding venous malformations of the head and neck: a comprehensive insight. Med Oncol. 2017; 34(3): 42, doi: 10.1007/s12032-017-0896-3, indexed in Pubmed: 28181207.

30. Nahm WK, Moise S, Eichenfield LF, et al. Venous malformations in blue rubber bleb nevus syndrome: variable onset of presentation. J Am Acad Dermatol. 2004; 50(5 Suppl): S101-S106, doi: 10.1016/S0190, indexed in Pubmed: 15097941

31. Lloyd DFA, van Amerom JFP, Pushparajah $\mathrm{K}$, et al. An exploration of the potential utility of fetal cardiovascular MRI as an adjunct to fetal echocardiography. Prenat Diagn. 2016; 36(10): 916-925, doi: 10.1002/pd.4912, indexed in Pubmed: 27521762.

32. Zhu M. Fetal cardiac MRI. Journal of Cardiovascular Magnetic Resonance. 2015; 17(Suppl 1): P220, doi: 10.1186/1532-429x-17-s1-p220.

33. Dong SZ, Zhu M. Pattern-based approach to fetal congenital cardiovascular anomalies using the transverse aortic arch view on prenatal cardiac MRI. Pediatr Radiol. 2015; 45(5): 743-750, doi: 10.1007/s00247-014-3131-9, indexed in Pubmed: 25149162.

34. Dong SZ, Zhu M, Li F. Preliminary experience with cardiovascular magnetic resonance in evaluation of fetal cardiovascular anomalies. J Cardiovasc Magn Reson. 2013; 15: 40, doi: 10.1186/1532-429X-15-40, indexed in Pubmed: 23692653. 